\title{
Comparative Analysis of Similarities and Differences between Null Hypotheses, Assumption of Breach
}

\author{
Ahmad Hedayatpanah Shaldehi, Mohammad Saeed Hedayatpanah Shaldehi, Marziyeh Hedayatpanah \\ Shaldehi
}

\begin{abstract}
The main purpose of this paper is to comparatively study the similarities and differences between of the , null hypothesis and assumption of breach .The null hypothesis, in applied researches, particularly experiments for confirm or rejection .a hypothesis, regard to inferential statistics That used in many different fields of humanities researchers, particularly psychology, education, management and sociological placed assumption of breach, to prove geometric proposition( theorems), which hypothetical temporary, that with the help of reasoning, the false statements, it we conclude. Such a statement may deny our hypotheses or assume reduction ad absurdum. The use of these two words separately and hypothesis alternative in abundance, the world of science and research, has been discussed, but the relationship between these words, mention, yet Isn't .This article describes the relation of these assumptions. Likewise, in writing, to the similarity, their differentiation, are mentioned. Including the results, that is, the achieve results null hypothesis, researcher with the error is encountered, but In the Reduction ad absurdum the achieve results, not an error.
\end{abstract}

Keywords: Geometry, Statistics, the Null Hypothesis, Assumption of Breach, Opposite Assume (Hypothesis Alternative)

\section{INTRODUCTION}

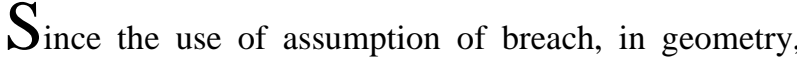
mostly mathematicians, use it, the null hypothesis, though, Stats headlines, its use in research, and applied training Educational Science, behavioral and etc. Are. In this paper, first, toExpressing the concepts of geometry, research methods, will be discussed. Then, it refers to the concept, relation, and, the funds means of common, and the distinction between the futures." Comparative analysis can be divided into quantitative, qualitative and fuzzy. Quantitative comparative analysis is variable-based, qualitative comparative analysis is case-based, and fuzzy adaptation is set.

Manuscript received on 14 September 2021 | Revised Manuscript received on 28 September 2021. Manuscript Accepted on 15 October 2021 | Manuscript published on 30 October 2021

* Correspondence Author

Ahmad Hedayatpanah Shaldehi*, Department of mathematics and Computer, Faculty of Moin Rasht Branch, Technical and Vocational University (TVU), Guilin, Iran Email: Ahmad.hedayatpanah@gmail.com

Mohammad Saeed Hedayatpanah Shaldehi, Department of mathematics and Computer, Faculty of Shaheed khodadadi Anzali Branch, Technical and Vocational University (TVU), Guilin Email: Hedayatpanah@gmail.com

Marziyeh Hedayatpanah Shaldehi, Department of mathematical and Computer, Faculty of Moien Rasht Branch, Technical and Vocational Vocational University (TVU), Guilin Email: m.hedayatpanah.86@gmail.com

(C) The Authors. Published by Lattice Science Publication (LSP).This is an open access article under the CC-BY-NC-ND license(http://creativecommons.org/licenses/by-nc-nd/4.0/)
In quantitative comparative analysis, social survey data, available statistical data, and historical quantitative data can be used. In quantitative comparative analysis, it can be done both descriptively and descriptively"[37]. In descriptive analysis, the main purpose of the study is how to distribute experimental data among analysis units. At the level of explanation, the causal relationship is examined.

\section{METHODOLOGY}

The research methodology is a library, analytical, and comparative study of interdisciplinary the content and subjects. Comparative analysis in terms of the type of research design can be based on two types of strategies. Strategy of the most similar systems and the most different systems (Perzowski, 1970) in the design of the most similar systems, the units of analysis have the maximum similarity with each other [37]. The comparative method is a branch of the social sciences, which refers to differences and similarities [32].

\subsection{Brief about Geometry}

Geometry was empirical subject, whose approximate answers were usually for practical purposes. The Greeks, and most of all the Thales Miletus, in 585 BC. They insisted that geometric sentences should be proved by analogical reasoning, not through experiment and error.

Tales to recognize the results right from false. He founded the first, logical geometry, Systemic and, Fundamentals Function Which began with Tales, Two centuries, continued by Pythagoras and his disciples. Regularizing the plane geometry by the Pythagoras doctrine, the mathematician of Hippocrates, Arranged about 400 years BC. [11].. However It was about the fourth century BC that it flourished, The Academy of Sciences and Philosophe of Plato's, The Plato repeatedly founded, proves to be dumb, the length of the square diameters to the sides of the unit, for example, for an indirect method (Reduction ad absurdum) . ( [ 11] .[41]).. On the other hand, Euclid was one of the first disciples of Plato, of the smallest, but of Archimedes, greater.[ 41]. .That about 300 years BC. The decisive method of Greek geometry, and the number theory, in its thirteen editions. By arranging this masterpiece, Euclid, the experience and the important work of his predecessors, fits in the centuries. What is taught in high school is Euclidean geometry (parabolic), which is in fact derived from the Euclidean Book of Principles, and more for the embodiment of the material world is used.

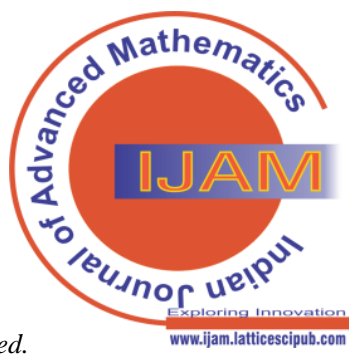


In contrast, any geometry, except for Euclidean geometry, is called non-Euclidean geometry. [11].

In the early nineteenth century (1829), revolutionary and important events took place, and two other geometries, called hyperbolic geometry, and elliptical geometry were suggested [13]. In this paper, Euclidean geometry is considered.

Watermark embedding algorithm -

\subsection{Brief about Research Methhod}

The word "research", Means , in the sense of truth, investigation, and interrogation [25]. Research has a long history. For the first method of reasoning has been attributed to Aristotle and to the Greeks, which is a deductive method, and the method of logical is the first method that was customary among philosophers. Deductive reasoning. A logical relationship between Major premises, Minor premises and Result, establishes.Centuries later (1620) Francis Bacon proposed a method of induction as a new method, which was considered by the scholars of time. Consequently, Aristotle's deductive method, and Bacon's inductive method, are interwoven with the works of Charles Darwin in the nineteenth century. Now, method the deductive -inductive is known as an example of a scientific method. Finally, John Dewey proposed a model that is useful for understanding the elements of the deductiveinductive process [4].

.However, the definition of research is methodologically problematic, and, in this respect, in the opinion of scholars and scholars, disagreement there is a lot. For this reason, it is not easy to provide a definition that is approved and wellconsidered by all researchers [7]..In this speech, some definitions are mentioned. "Research is any systematic activity in a thematic study to achieve general principles [40]."Scientific research, systematic, controlled, empirical, and cognitive study of natural phenomena That, the probable relations between these phenomena are guided by the hypothesis and the theory "[ 21]. "Research as an analysis, an objective recording, and a systematic observation of controlled observations, which may lead to the development of general rules, principles, or theories, and its consequences for forecasting, and, eventually, the final control of events) [16].

\section{QUESTIONS}

1. Assumption of breach what is?

2. Null hypothesis of, what is?

3. Opposite assume, (hypothesis alternative) what is?

4. Similarity, assumption of breach and null hypothesis, what is?

.5. What distinguishes, null hypothesis of, and assumption of breach, what is?

\section{REDUCTION AD ABSURDUM}

Reduction ad absurdum one of the methods of proof in mathematical science and logic is the argument. This method is called indirect proof. In the method of the reduction ad absurdum, in order that, to prove that it is a correct proposition, we prove that the opposite is the case, scilicet the negation is incorrect. Reductions ad absurdum usually used to prove an inverse of a proposition and is used in two conditional propositions or theorems (Greenberg, 2007). Plato, often the proof of being dumb to the sides of the unit the length of the square diameter was unambiguously established to the opposite sides of the unit as an example for an indirect method (the argument of the posterity). The implicit argument was, therefore, invented by Plato.[11]. In the so-called classical logic, reductions ad absurdum is the proof of a verdict, by extracting the contradiction from, the negation between that verdicts. And the sentences previously it's been proven, or accepted, and this is also indirect proof .The phrase ". Reductions ad absurdum "is also used to prove the negation of a proposition, and to the sentences already proven. Also Refers to, [23]. , In many cases, for proof can be used both in direct and indirect fashion [4].

\subsection{Assumption of Breach? (Answer the first question)}

In reduction ad absurdum "When they want to prove a conditional proposition, such as $\mathrm{H} \rightarrow \mathrm{C}$, The negation verdict, they think correct the negation, that is, And, because the new assumption is not mistaken with $H$, it is called. The reduction ad absurdum (or Assumption of breach) .The temporal hypothesis is that, with the help of the_Reasoning , we derive the absurd proposition from that (absurd , that is, the negation of a statement, which that correction, for we is certain).Such a proposition may negate the assumption of a proposition, or the hypothesis reduction ad absurdum of ours . It may a proposition that it has already been proven , or even negate postulate . However, it has been shown that negation of $\mathrm{C}$ leads to a void of the absurd proposition, hence the proposition or propositional function of C's conclusion._That's what. Reduction ad absurdum is called .[11].

The method of the reduction ad absurdum, in proving that the proposition or proposition of $\mathrm{Q}$ is the result of the of assumed, That is, $\sim \mathrm{Q}$ (the negation of the desired result), sometimes called the promise of the claimant, and we call it the reduction ad absurdum are assumed, and, based on this assumption, extracts from the assumptions, events, previously fixed or accepted. And, in this regard, the verdict is abjuration of the promise of the claimant, and the proof of the result is desirable. [24]. the fact that a mathematical phrase cannot, at the same time, be both correct and untrue is the basis of the indirect method of proof]. ([25],[4]).."All mathematical theorems, conditional propositions, are propositions of the form, if [hypothesis], then [The verdict] [23]. For example, The adjacent angles to the base, in a isosceles trapezoid congruence , can be interpreted as follows:

If a triangle is two side, then the angles facing these two side are congruence [11]..

In the books, the old saying of logic, proposition, theorem [25]. Underneath, the theorem is based on the proof of reduction ad absurdum .Proposition: "two lines perpendicular parallel line break." [2].

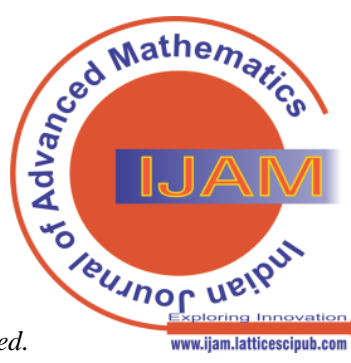




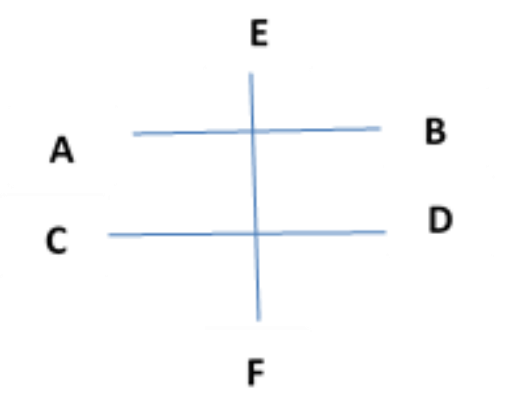

Figure (1)

Assumption (assumption of breach): The two lines distinct $\mathrm{AB}$ and $\mathrm{CD}$ are perpendicular the $\mathrm{EF}$ line. Statement: $\quad \mathrm{AB}\|\quad\|$ CD proof: (Method of Reduction ad absurdum). If the two lines $\mathrm{AB}$ and $\mathrm{CD}$ are not parallel, that they cut one another at a point, which we call P. Figure (1). In this case, it is necessary that, from point $\mathrm{P}$, the two lines perpendicular on $\mathrm{EF}$, and this is impossible. Therefore, there is no point of intersection of $\mathrm{P}$, and by definition, the two lines $\mathrm{AB}$ and CD are parallel " [2].

\section{HYPOTHESIS}

Before expressing the null hypothesis, we explain the concept of hypothesis.

\section{Comments:}

A hypothesis, a testable proposition, or a preliminary statement, is about the relationship between the two variables. Hypotheses, guesses about how to_working ( activity) of the social world are, and are expressed in a form free of value [42]. "In the logic , major premises , in its old deduction method gradually replaced its Default, or hypothesis Which was tested by collecting and analyzing logical data.[4].A hypothesis, usually, appears in the form of thinking, which arises from the observation of phenomena, in nature) [20]. "The hypothesis is, in fact, the Proposed researcher 's solution to solve the problem. The hypothesis is a powerful tool that enables the researcher to relate the theory to observation and observation, to the theory. The hypothesis is a conditional proposition, or hypothetical, that verification, or rejection, must be tested on the basis of the adaptation of its concepts,_Based on empirical documents of the past, be tested [8]In simple language, it can be said that the combination of one The presumptive manifesto (statement ) Hence is: If Such, and so , and this happens, the result will be so and so [28].. The best way to express the hypothesis is to" if ... then (in that case) ... "Express the hypothesis, in the form of if ... then ... says that "if Such, and so (a), in that case, it will be such and such and a person Any one will be" (b) "Of course, most of the hypotheses contained in behavioral knowledge are not used in this form. For example:

"Watching Watch movies, violent TV Causes of Quarrel aggression in children . "Exactly, in the form, if (a) then (b) not stated. . This hypothesis In the form of "If children watch violent television films (A), In that case, their aggressiveness will increase (B).[12]. .John w, Best Writes : After it was known, it may be possible to set certain answers or solutions as hypotheses .Putting in order. These suppositions, prudent guesses or thoughts may be based on previous experiences, formal observations or information obtained from others. Therefore: The hypothesis of research, or the scientific hypothesis, is a; a statement, or a the official statement of positive, To predict the outcome of a unique research, or an experimental explanation of the relationship between two or more variables; the hypothesis implies that research on a the goal is to be focused, and what must be observed to be determined. [16]..Tuchman, Wireman, writes: to express the relation between two or more variables. In the form Clear, and without ambiguity, as a predicate, clear, and unambiguous statement, to be tested, this means that it is possible to express it again operationally._And regardless of ethical judgments, it is legal [12]. Since the hypothesis is a researcher's proposed solution to solve the problem,_we express a problem and hypothesis in this section. The problem :"Is the efficiency of teachers who have completed the teacher training period more than the performance of teachers who have not seen this course? "Hypothesis: The effectiveness (Performance) of teachers who have completed their teacher training period is more than teachers who have not seen this course. [8].

\subsection{Features of the Hypothesis}

The most important Property of a good hypothesis is its testability.[8]. Many, quantitative researchers, especially those who do on a testing strategy, express their hypotheses, based on the logic of negation of hypothesis, in the null hypothesis. [42]The hypothesis can be extraction by collecting information, and the experimental observations, rejection, or confirmation, and a result from it, if the hypothesis is correct, then the results are predicted. So, as long as the variables of the research cannot be measured, it is impossible to test the hypothesis. [7]For example, the sentence ."Execution counseling and guidance in elementary schools is ideal" In the form of valuable concepts, and cannot be Researched [9]. If this is a general hypothesis, It is difficult to test it, and even in some cases, it is impossible, therefore, the more slight the problem is, the further, the possibility of testing it, but the changing the whole, to the petty, must continue to some extent, which reduces the importance of the problem, or the hypothesis, does not lead to ([6].[7], [8]). "The hypothesis test is an inductive process, the purpose of which is to estimate the parameter of the society that the sample studied has been extracted from [6]. The Assumption difference, with hypothesis, is that, assuming, there are sets of guesses that do not have theoretical support, and the investigator expresses them with their general consciousness, while the hypothesis is based on the theoretical framework, which is the result of the research. Also, assuming, in the "hypothesis test" is the statistical form of the hypothesis [18].

\subsection{Types of Features}

\section{A: Investigative}

A: The investigative hypothesis is divided, to directionally, and without direction, and directionally, into positive or negative.

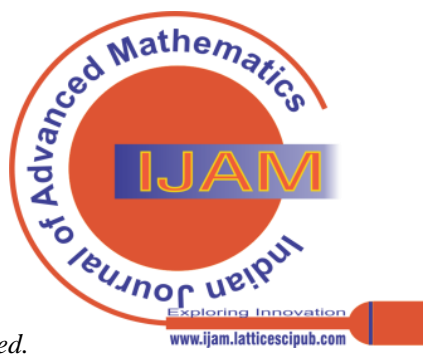




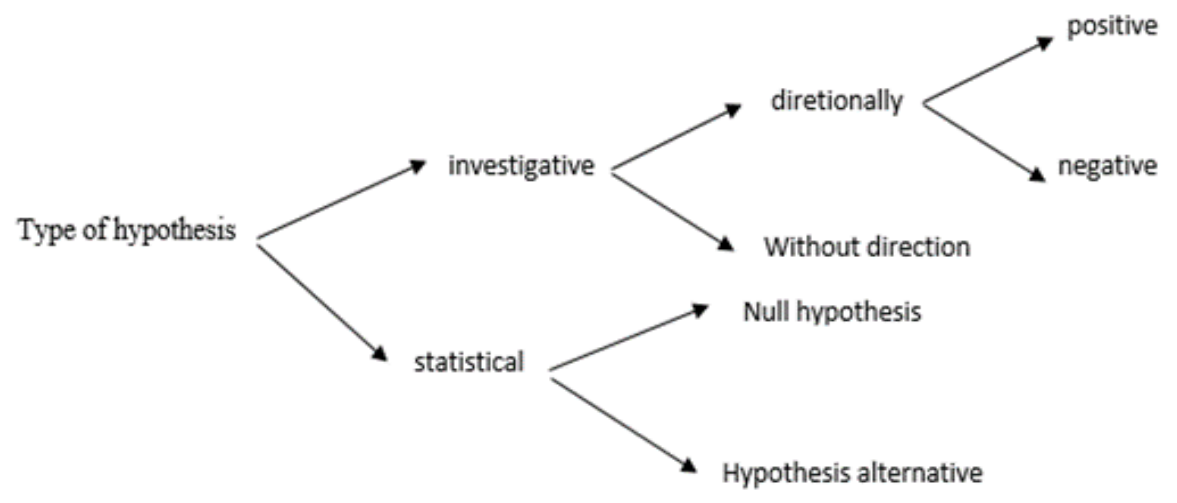

Figure (2)

\section{B: Statistical}

B: The statistical hypothesis is divided into the null hypothesis, and the opposite hypothesis.

Research hypothesis

Research hypothesis "is, a guess, or thought, about the relation between research variables, which are divided in directional and non-directional directions" [8].This hypothesis is divided into two types, positive directional and negative directional ( [14] .[10]). .Example1: "Increasing social skills teaching will increase students' self-esteem [15]) .Example2: Reducing the duration of homework assignments, in class, reduces the behavior of out-of-school students. [9] In an unpaired hypothesis, the direction of effect, or the relation of the independent variable, or the dependent variable, is not known. Example: " There is a relationship between self-esteem and the students' homophony" [12]).It can be seen a unidirectional hypothesis shows that there is a waiting for a change, but not for change.

\section{The Statistical Hypothesis}

The statistical hypothesis is "a hypothesis that denies the existence of a relationship or effect between variables" [34]. It includes: the null hypothesis, and the hypothesis is opposite (hypothesis alternative ([14].[26]). In other words, the test of a statistical hypothesis is the use of a set of explicit rules for it, which determines whether to accept the null hypothesis,_Or is it, in favor of the alternative hypothesis, reject( John Freund ,2005) [17].“"The real hypothesis is the ordinary type of hypothesis, in which, the relation between two or several variables, a conjecture rule, is expressed in terms of".. Example: "Whatever the size, the group bond is greater, the Group influence is greater on its members," which is a real hypothesis. The Real hypothesis, in itself, is not testable,. It should be translated as a so-called operative. One of these ways is using the statistical hypothesis. The Statistical hypothesis, an aspect of the original real hypothesis, into, quantitative, and statistical, state [21].

\section{THE NULL HYPOTHESIS}

\section{(Ho): (the answer to the second question)}

Various views,_There is in_about of the null hypothesis, some of which are: In the context of the test of assumptions, often, with hypotheses or claims, we are faced with the parameters of the distribution of statistical societies. This assumption, or claims, is a the null hypothesis. And, show it with Ho. And, it is assumed that we intend to, reject, or not deny it[31]. Such as "between self-esteem and the students' homophony does not exist relationship" [12].

Unlike to the research hypothesis, it explicitly rejects and denies the existence of any relationship, effect, or difference between two, or variable variables (or variables), and states that these are not real cases, and it's not true. Instead, any difference, relationship, or effect is merely the result of accidental events, or errors. , And, due to accident, and, statistical errors, especially in sampling [36]. However, the researchers, tests the hypothesis in two ways: the direct method, and, the null hypothesis method. Many quantitative researchers, especially those who undertake an experimental strategy, express their hypotheses, Based on the logic of the negation hypothesis, they are expressed in the null hypothesis.Then they test the hypothesis with empirical evidence, which allows them to accept, or reject the null hypothesis. Most people consider hypotheses a way to predict a relationship. The null hypothesis case mode is the opposite. This hypothesis does not predict any relation [42]."The null hypothesis is a quantitative statement a form of expression, which is formulated as a parameter, and its mathematical construct is Reduction ad absurdum[8].. The null hypothesis, unlike the hypothesis of the research, suggests the absence of a relationship between variables, Points out. This hypothesis states that the independent variable does not have an effect on the dependent variable, and there are no variables, relationships, or differences[12] .Example:" Children who go to kindergarten, in comparison, with similar children, Do not go to kindergarten, gain academic achievement in first-grade readings, Impressive results, gain. [27]. The null hypothesis, in the above hypothesis, is: "There is no significant difference between the children who go to kindergarten and those who do not go there, in the scores obtained, in academic progress, in the first grade reading." [26] "The null hypothesis, It says that the correlation coefficient is equal to zero [16]. Since the null hypothesis is taken by statistical tests, it is used, the researcher uses it to interpret the results .[14] , [35] ).

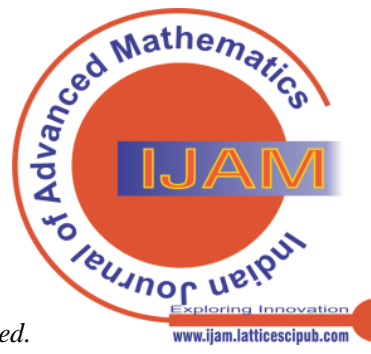




\subsection{Statistical Significance}

In an experiment, random sample, of individuals, sometimes, of difference, between the_Averages, is so much that, they can, result from the difference in situations. These differences are statistically significant. [26] .In humanscience research, if the observed difference is possibility to be 5 percent, due to the sampling error, or, in other words, if, with a probability of $95 \%$ confidence, the observed difference is not due to the sampling error, the difference is significance, and the null hypothesis is rejected, meaning the difference is significant. Example: For example, in a test, the observed frequencies (Fo) are as follows:

FO:

18-20-24-26-27-29

and, the expected frequency (Fe), if, using the formula $x^{2}=\frac{\left(F_{O}-F_{e}\right)^{2}}{F_{e}}$, we calculate the Chi -square ( $x^{2}$ ) test, the number is obtained at 3.75. Because, the degree of freedom is 5 , and the confidence level is $95 \%$. We say, because the result is less than the table (11.07), so the null hypothesis is not rejected,(_It is confirmed.) That is, the difference is meaningful. In other words, there is no significant difference between the observed frequencies and the expected frequencies. And, opposite assume, is confirmed [29].

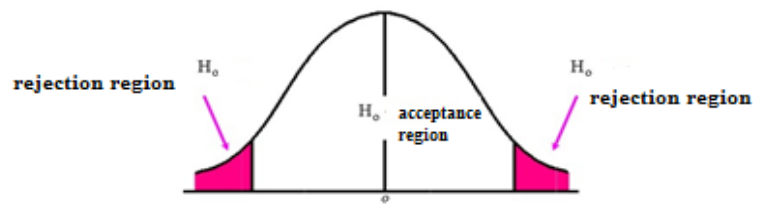

Graph (1)

\section{THE OPPOSITE ASSUMPTION OR HYPOTHESIS ALTERNATIVE $\left({ }^{H_{A}}\right)$.}

(The answer to the third question)

The statistical hypothesis, which, in contrast to the null hypothesis, is called (contrary to the null hypothesis), is called the opposite assumption, or hypothesis alternative and it shows by $\mathbb{H}_{\mathbb{A}}$, in other words, the hypothesis $\mathbb{H}_{\mathbb{A}}$ is a hypothesis that, if rejected, $\mathbb{H}_{\infty}$ is accepted (accepted). And, or statistically, in a more correct way, is not rejected [31]. The opposite hypothesis ( $\mathbb{H}_{\mathrm{A}}$ ) is in accordance with the research hypotheses, which means that if the research hypothesis is directional, this hypothesis will also be directional. The null hypothesis, or the no-difference hypothesis[8]. In other words, the opposite assumption $\left(\mathrm{H}_{\mathrm{A}}\right.$ ) is an expression that the researcher wishes to study about it. The null hypothesis, and the hypothesis alternative must be incompatible, meaning that they should not interference in any way, with each other. The opposite assumption $\left(\mathbb{H}_{\mathbb{A}}\right.$ ) is often consistent with the research hypotheses, that is, the opposite assumption $\left(\mathrm{H}_{\mathrm{A}}\right)$ is the author's expectation of the results of the research. And, usually, this expectation is obtained on the basis of the evidence, and / or the work experience, of the researcher ([17].[1]). The opposite assumption $\left(\mathrm{H}_{\mathbb{A}}\right)$ is, in fact, the same verdict, in, geometry

\section{RESULT}

\subsection{Similarity, (the Answer to the Fourth Question) In the Table (1)}

Table (1)_Shows similarities

\begin{tabular}{|c|c|}
\hline $\begin{array}{c}\text { null hypotheses In research } \\
\text { method }\end{array}$ & $\begin{array}{c}\text { assumption of breach In } \\
\text { geometry }\end{array}$ \\
\hline $\begin{array}{c}\text { The hypothesis is expressed } \\
\text { with a news sentence. }\end{array}$ & $\begin{array}{c}\text { The theorem, or, the } \\
\text { proposition is expressed with a } \\
\text { sentence. }\end{array}$ \\
\hline $\begin{array}{c}\text { The content of the hypothesis is } \\
\text { conditional }(\mathrm{p} \rightarrow \mathrm{q})\end{array}$ & $\begin{array}{c}\text { The content of a proposition, or } \\
\text { a theorem, is a conditional ( } \mathrm{p} \\
\rightarrow \mathrm{q})\end{array}$ \\
\hline $\begin{array}{c}\text { In the null hypothesis, we deal } \\
\text { with the negative hypothesis }\end{array}$ & $\begin{array}{c}\text { In assumption of breach, we } \\
\text { deal with negation statement. } \\
\text { [11]. }\end{array}$ \\
\hline
\end{tabular}

8.2. Differentiation. (Fifth Question Answer) Table (2)

Table (2) shows the differences

\begin{tabular}{|c|c|}
\hline null hypotheses research method & $\begin{array}{l}\text { assumption of breach in } \\
\text { geometry }\end{array}$ \\
\hline $\begin{array}{l}\text { Hypothesis, never, cannot be } \\
\text { proved, but can, be violated, or } \\
\text { confirmed [29]. }\end{array}$ & $\begin{array}{l}\text { The verdict does not prove } \\
\text { directly. Only the. assumption } \\
\text { of breach is rejected }\end{array}$ \\
\hline $\begin{array}{l}\text { By sampling, or census we are } \\
\text { faced. }\end{array}$ & There is no sampling. \\
\hline $\begin{array}{l}\text { For the result, the null } \\
\text { hypothesis, the (rejection or } \\
\text { confirmation) of the rejection, or } \\
\text { the correctness of the article, is } \\
95 \text { or } 99 \text { or ... percent }\end{array}$ & $\begin{array}{l}\text { For the result, in the. } \\
\text { Assumption of breach , we } \\
\text { will become false, or the } \\
\text { content is correct, } 100 \% \text {. }\end{array}$ \\
\hline $\begin{array}{c}\text { We deal with independent, } \\
\text { dependent and dependent } \\
\text { variables } \\
\end{array}$ & $\begin{array}{l}\text { with, assuming, and, with, the } \\
\text { sentence, we deal with Both }\end{array}$ \\
\hline We are faced with an error & We are not faced with an error \\
\hline $\begin{array}{l}\text { We use significant words, and, } \\
\text { confirm, or, reject }\end{array}$ & $\begin{array}{l}\text { We will deal with the word } \\
\text { proof }\end{array}$ \\
\hline $\begin{array}{l}\text { Based on statistical tests (analysis } \\
\text { is done) }\end{array}$ & $\begin{array}{c}\text { No statistical tests (no statistical } \\
\text { analysis) }\end{array}$ \\
\hline $\begin{array}{l}\text { For all the hypotheses, it is } \\
\text { applicable. }\end{array}$ & For all the cases, it is not usable \\
\hline $\begin{array}{l}\text { In a quantitative research, it } \\
\text { needs to be interpreted }\end{array}$ & $\begin{array}{l}\text { It does not need to be } \\
\text { interpreted }\end{array}$ \\
\hline
\end{tabular}

\section{CONCLUSION}

The Reduction ad absurdum , which for indirect proof, is used in geometry. , Which arrives at the false result, because it relates to the proof of the geometric propositions, which, with the rejection of the hypothetical assumption, we find indirect proof, $100 \%$ of the proposition, of the hand. , And, never, the discussion of the error is not working. However, in the research, since we use sampling, instead of Reduction ad absurdum, we use the term the null hypothesis, which is the negation of the operational hypothesis, and we must use statistical tests to obtain the result Generalize. Perhaps the null hypothesis, rejected, or, verified, but, since sampling is accompanied by error. Therefore, for, we cannot, for, deny the null hypothesis, we can find the result, or definite argument, $100 \%$, in other words, it is not proved, but confirmed, or rejected. For this reason, in inferential statistics, errors of $5 \%$ and $1 \%$ have been predicted, and, instead, the term geometric proof is used in meaningful terms.

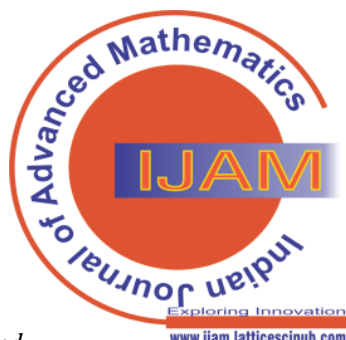


Therefore, the Reduction ad absurdum, and, null hypothesis, are not the same. And the result is that the "the null hypothesis is a quantitative statement, which is formulated as a parameter, and its mathematical form is the Reduction ad absurdum [7]. Is not the same. , But there are similarities and differences. According to what has passed, we must add that the assumption of breach. The equivalent is the negation of the verdict in geometry. , and null hypothesis ,equivalent is the negation of the hypothesis, in the research process, and opposite assume, (hypothesis Alternative ) is the equivalent of the verdict in geometry, which the researcher wishes to achieve It has it.

\section{REFERENCES}

1. Alevi, P. (1988). Research Method of the New Science Publishing Institute First Printing.

2. Azarnoosh,M and Bierashch,A.... (1967). Literature Geometry.

3. Behboodyan, J. (2005). Statistics and Preliminary Probability of Astane Quds Razavi Publications.

4. Boris ESkill, J. (1988) Introduction to Mathematical reasoning, Translator G, Yasipour Publication of Madrase ,Niloufar Publications. Publishing.

7. Delaware,A. (2005). Theoretical and Applied Research Principles, Roshd Publishing.

8. Delaware, A. (2004). Research Methods in Psychology and Educational Sciences. Payame Noor University Press.

9. David, A.and Bony, F.(2000). Statistical Experiments and Designs Translators: Talebi; Alamatsaz and Mousavi, University of Isfahan University Press

10. Farhadi, H. (2002). Principles and Methods in Applied Linguistics of Translators: Javaheri,F. and Khan Mohammad.Hajar ,Rahnama Publications.

11. Greenberg.m.j(1979).Euclidean and Non- Euclidean, Translator:M.H.shafieiha.( 1984) University Publishing Center. Savalan Publishing.

13. Harold, A. Wolf (2007). Introduction to Non-Euclidean Geometry, Translator: Bierashch, A. Amir Kabir Publications.

14. HedayatPanah, A. (2011). How to research? Darayye danesh Publishing.

15. Ismaeli,A. and Biabangard,A. (2003). Statistics and Research Methodology, Publication sanjesh.

16. John Best. (1997) Research Methods in Educational and Behavioral Sciences, Translators Sharifi and Taleghani. Roshd Publishing.

17. John Frond. (2005). Mathematical statistics, translators Amidi and Vahidi Principal Center for Academic Publishing.

18. Khaki, G- R. (2012). Research Method in Fujian Publishing Management.

19. Khalatbari, J. (2011). Major Issues in Sad Publication Statistics.

20. Kazem Mohammad, Malek Afzali and Nahpatian .(1998). Statistical Methods and Health Indicators Publisher of Authors.

21. Kerlinger,F. (2003). Research Basics in Journalistic Behavioral Sciences (1) and (2) Translators: Pasha Sharifi , Najafi Zand, Avaya Noor Publications.

22. Marvin, J, Greenberg. (2007). Euclidean geometries and Euclidian interpreter. M- H Shafieeae, Academic Publishing Center.

23. Mosahab,G-H. (1988).Logic of the Form of Hekmat Publishing.

24. Mosahab,G-H .(1984). Mathematical Analysis of Amir Kabir Publishing.

25. Moein, M. (1984). The Persian Culture of Amir Kabir Publishing.

26. Meredith .d.Gall. w.R. Borg, And J.P.Gall .(2005). Quantitative and qualitative research methods in education and psychology Volume (I) Translator Nasr A- R, and others, Shahid Beheshti University Publications (samt).

27. Meredith Gal, Borg Gal. (2007) Quantitative and qualitative research methods in education and psychology Volume (II).Translator: Nasr and others ,Shahid Beheshti University Publications and (samt).

28. Nader, E ... and Seif, Naraghi, M (1988) Research Methods and Methods of its Evaluation in Human Sciences, Badr Publications.

29. NegarashNejad,A- M .(2000). Basic Statistical Methods in Educational Sciences Sufi Publications.

30. Nabavi, B. (1988). Introduction to Research Method in Social Science Publication.
5. Catnap, R. (1983) Philosophy of Science translation Yousef. A

6. Delaware ,A. (2011). Probability and Applied Science, Roshed

12. Hassanzadeh, R. (2009). Research Methods in Behavioral Sciences,

31. Ranjbaran ,H. (2008). Statistical and probability, academic publication.

32. Ragin. Charles (1989) the Comparative Method. Translated by :Mohammad fazeli.Agaah Publishing. House .Tehran (2009

33. Riff, D. Lacy, S. and Fico Friedrich, J .(2002). Analyzing of Media Messages, Translator: Boroujerdi, M. Soroush Publishing.

34. Saroukhani, B. (2003). Research Methods in Social Sciences Volume (3), publishing Didar.

35. Sarokuhani, B. (2006). Research Methods in the Social Sciences of Masses (1) and (2) Research Institute of Humanities and Cultural Studies.

36. Sabri, N-M. (2009). The method of research in the law of, publishing Mizan .

37. Saei, Ali (2013). Comparative research method, Tehran, Ad Publishing.

38. Safari, A.and Ghorbani, A. Solving The problem Geometry, Scientific Publishing Without Publishing Year.

39. Sarmad, Bazargan and Hejazi. (2006). Research Methods in Behavioral Sciences. Publishing Agah

40. Taleghani, M. (2002). Theoretical Research Methods, Payame Noor University Press

41. Thomas, L, Heath (2008) Euclid's Principles, Translator: Shafieei,MH. Council of Iranian Mathematical Housesof Farvardin Library.

42. W- L- Newman. (2010). Qualitative and Quantitative Approaches, Translators: Danniefard,H. and Kazemi,H. Mehraban Publishing.

\section{AUTHOR'S PROFILE}

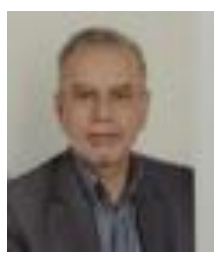

\section{Name: Ahmad}

- Last name: HyatPanah Shaldehi

Place of birth: : 1957,Iran, Gilman

-- Field of study: Mathematics (diploma to doctorate)

- - Skills and interest: Statistics

and research methods in the

behavioral sciences of chord and

-- Teaching: 44 years (university

and education)

Researches:

- Conductor of various researches: 32 cases

Published books: 15 items,, like:

- Congnitive Style (FI\&FD) Mathematical According Bloom's

Taxonomy ,Publisher (lap) in Germany -General

Mathematics(1):ISBN : 978-964-9592-82-4 Publisher : Daryaye

Danesh - General Mathematics(2):ISBN : 978-964-6977-39-1

Publisher : Abrang

- How we research? ISBN :978-964-9592-

85-5 Publisher : Daryaye danesh - Statistics

and Probability ISBN: 978-964-95928-3-1

Publisher : Daryaye danesh -Pre

Mathematics . ISBN : 978-964-9592-84-8

Publisher : Daryaye danesh

-Why learn math? ISBN : 964-6677-12-x : Publisher : Abrang danesh

Awards, 47 items , like:

1. The Best researcher Iranian 2012

2. The best University2012 of

superior technical and professional

Researchers 3) The Best

University2013 of superior

technical and professional

Researchers (4 The Best researcher

Iranian (Guilan) 2012

(5TheBest researcher Iranian (Guilan) 2013

6) The Sample Teacher Iranian 2003

7) The Sample Teacher Iranian 2006

8) The Sample Teacher Iranian 2012

9) Author of the article Top in Iran2000

10) Author of the article Top in Iran2004

11) Author of the book Top Iran 2019

12) Author of the book Top Iran 2018

13) Author of the book Top Iran ,...

- Workshop: 48 items

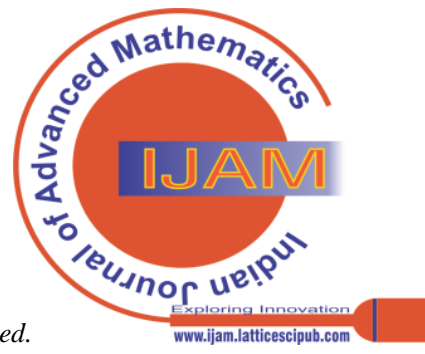


Judging articles:

: Over 1300 cases (provincial, national and international)

Articles: like

1.Fuzzy approach to Likert

Spectrum in Classified levels in

Surveing research A

hedayatpanah

The Journal of Mathematics and Computer Science 2 (2), 394-401 2011

2.Study and investigation of the problems and learning disorders of

students by various cognitive styles in mathematics course at Rasht

shahid chamran higher education center

The Journal of Mathematics and Computer Science 1 (3), 216-229 2010
3.Using Eta $(\eta)$ correlation ratio in analyzing strongly nonlinear relationship between two Variables in Practical researches

AH Shaldehi

Journal of mathematics and computer science(tjmcs) 7 (3), 213-220 2013

4.Students' Field-dependency and Their Mathematical Performance based on Bloom's Cognitive Levels R farhad, Alamolhodaei Hassan hedayatpanah Ahmad

Korean Society of Mathematical Education 15 (4), 373-386 1

2011

- Presenting papers in national and international conferences: 51 cases

-- Published articles: 99 cases in Iran and 23 cases outside Iran

\begin{tabular}{|c|c|c|c|c|c|c|c|c|c|c|c|}
\hline $\begin{array}{c}\text { Scientific } \\
\text { database } \\
\text { name }\end{array}$ & PubMed & ISI & $\begin{array}{c}\text { Scopus } \\
\text { Elsevier }\end{array}$ & Icv & Isc & Sci & wos & Jcr & Esci & $\begin{array}{l}\text { Fuzzy } \\
\text { article }\end{array}$ & citation \\
\hline index & 1 & 4 & 5 & 1 & 14 & 5 & 1 & 1 & 4 & 20 & 34 \\
\hline
\end{tabular}

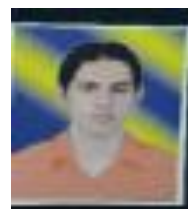

Name: Mohammad Saeed

Last name: Hedayat Panah Shaldehi

Place of birth: Iran, Gilan, Rasht

Bachelor: Computer Engineering

Master: Sports Management

Research: 6 cases

Published books: 2 items, : like:

- Malavan anzali( sports- ISBN : 978-600-92139-7-9 Publisher : Daryaye danesh Articles: 12 items .like:

1)The proposed model payment system for performance of the football players 2)Advanced Social Humanities and Management (ASHM) 3 (1), 70-77 Teaching: 6 years in different universities

Occupation: University lecturer

Skills: Sports Science and Computer Hardware

Awards: 4 items

Job: University lecturer

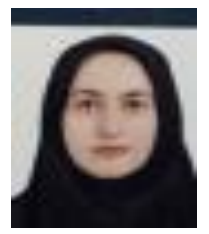

Name: Marzieh

Last name: Hedayat Panah Shaldehi

Place of birth: Iran, Gilan, Rasht

Bachelor: Computer Science

Master: Information Technology Engineering

Research: 4 cases

Articles: 19 items .lilk

The Survey of student's mathematics Calculations disorder" in International Journal of Advance Research in Engineering and Applied Sciences(ijareas), Volume2, Issue1,Pages 89-96, 2015 2. "A Study on the Characteristics of a Virtual Classroom" in International Journal of Innovation and Research in Educational Sciences, Volume 1, Issue 2, ISSN (Online): 2349-5219, 2014 3. "Performance Comparison of the mathematical skills of Computer and Electronics students in the Chamran college technical rasht" in Journal of Progressive Research in Mathematics (JPRM), An International Journal, Volume 1, Issue 1, December, 2014

Teaching: 7 years in different universities (technical and professional, free, Payam Noor, Simaye Danesh and Koushiar)

Job: University lecturer

Book printing: 2 items, : like

- Design and implementation of electronic library. ISBN : 978-600-7223-

04-8 Publisher : Daryaye danesh Publisher : Daryaye Danesh

Awards: 4 items

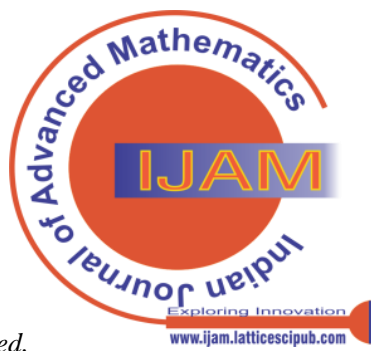

